\title{
Predictive value of D-dimer testing for the diagnosis of venous thrombosis in unusual locations
}

Citation for published version (APA):

Ordieres-Ortega, L., Demelo-Rodriguez, P., Galeano-Valle, F., Kremers, B. M. M., ten Cate-Hoek, A. J., \& ten Cate, H. (2020). Predictive value of D-dimer testing for the diagnosis of venous thrombosis in unusual locations: A systematic review. Thrombosis Research, 189, 5-12.

https://doi.org/10.1016/j.thromres.2020.02.009

Document status and date:

Published: 01/05/2020

DOI:

10.1016/j.thromres.2020.02.009

Document Version:

Publisher's PDF, also known as Version of record

Document license:

Taverne

Please check the document version of this publication:

- A submitted manuscript is the version of the article upon submission and before peer-review. There can be important differences between the submitted version and the official published version of record.

People interested in the research are advised to contact the author for the final version of the publication, or visit the DOI to the publisher's website.

- The final author version and the galley proof are versions of the publication after peer review.

- The final published version features the final layout of the paper including the volume, issue and page numbers.

Link to publication

\footnotetext{
General rights rights.

- You may freely distribute the URL identifying the publication in the public portal. please follow below link for the End User Agreement:

www.umlib.nl/taverne-license

Take down policy

If you believe that this document breaches copyright please contact us at:

repository@maastrichtuniversity.nl

providing details and we will investigate your claim.
}

Copyright and moral rights for the publications made accessible in the public portal are retained by the authors and/or other copyright owners and it is a condition of accessing publications that users recognise and abide by the legal requirements associated with these

- Users may download and print one copy of any publication from the public portal for the purpose of private study or research.

- You may not further distribute the material or use it for any profit-making activity or commercial gain

If the publication is distributed under the terms of Article $25 \mathrm{fa}$ of the Dutch Copyright Act, indicated by the "Taverne" license above, 
Short Review

\title{
Predictive value of D-dimer testing for the diagnosis of venous thrombosis in unusual locations: A systematic review
}

\author{
L. Ordieres-Ortega ${ }^{\mathrm{a}, \mathrm{b}}$, P. Demelo-Rodríguez ${ }^{\mathrm{a}, \mathrm{b}, \mathrm{c}, *}$, F. Galeano-Valle ${ }^{\mathrm{a}, \mathrm{b}, \mathrm{c}}$, B.M.M. Kremers ${ }^{\mathrm{d}}$, \\ A.J. ten Cate-Hoek ${ }^{\mathrm{d}}, \mathrm{H}$. ten Cate ${ }^{\mathrm{d}}$ \\ ${ }^{a}$ Venous Thromboembolism Unit, Internal Medicine Department, Hospital General Universitario Gregorio Marañón, Madrid, Spain \\ ${ }^{\mathrm{b}}$ School of Medicine, Universidad Complutense de Madrid, Spain \\ ${ }^{\mathrm{c}}$ Gregorio Marañón Institute of Sanitary Research (IISGM), Madrid, Spain \\ ${ }^{\mathrm{d}}$ Department of Internal Medicine, Laboratory of Clinical Thrombosis and Hemostasis, and Cardiovascular Research Institute, Maastricht University Medical Center, \\ Maastricht, the Netherlands
}

\section{A B S T R A C T}

Background: The value of D-dimer testing for the diagnosis of thrombosis in unusual sites is not properly established and evidence is scarce. We performed a systematic review of the literature.

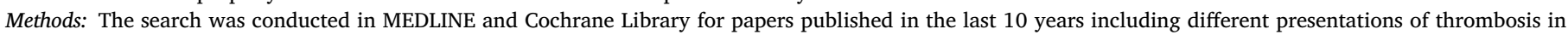

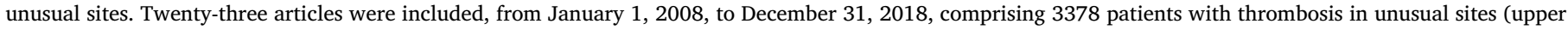

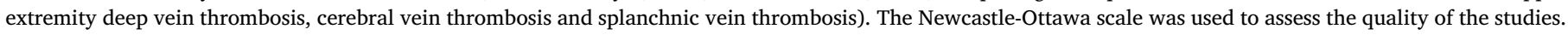

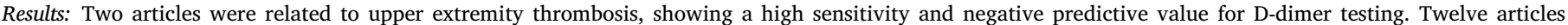

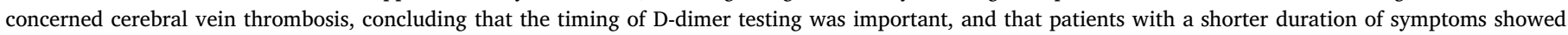

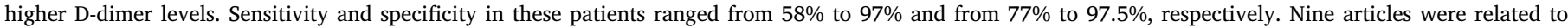

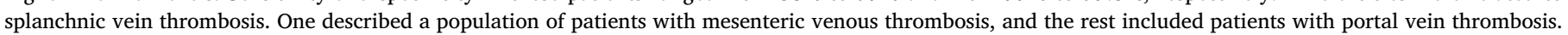
The D-dimer testing methods and the proposed cut-off levels were remarkably different among the included studies.

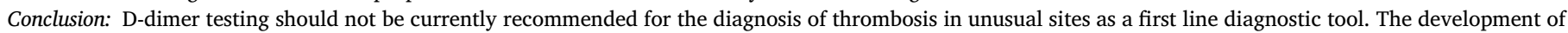
algorithms combining biomarkers such as D-dimer and clinical decision tools could improve the diagnosis.

\section{Introduction}

Venous thromboembolism (VTE) is a spectrum of entities that includes deep venous thrombosis (DVT) in any location and pulmonary embolism (PE) [1]. Incidence data vary according to age, location and other factors including comorbidities like cancer. Among these, thrombosis in unusual sites (TUS) comprise thrombotic events in atypical locations. The most common TUS are upper extremity deep vein thrombosis (UEDVT), cerebral vein thrombosis (CVT) and splanchnic vein thrombosis (SVT). There are nevertheless more types of TUS, including inferior thyroid vein thrombosis, retinal vein thrombosis, renal vein thrombosis or ovarian vein thrombosis, among others [2].

The clinical presentation depends on the type and location of VTE event. However, thrombosis may also escape clinical suspicion due to lack of symptoms (recumbent patients) or unspecific symptomatology. A two-step diagnostic approach is advocated. In first instance, history taking and physical examination are compulsory, but usually not sufficient to establish or rule out the diagnosis of VTE. Risk stratification may help identify those patients who have a high probability of VTE, with the help of scores such as the Wells score for DVT [2] or PE [3], and the Geneva score [4] and the YEARS algorithm [5] for PE. A second step in the diagnostic work-up is the use of a D-dimer assay. D-dimer consists of two covalently bound fibrin D domains, produced when plasmin cleaves fibrin [6]. There are numerous D-dimer assays, including whole-blood agglutination assays, enzyme-linked immunosorbent immunofluorescent assays (ELISA), and latex agglutination assays [7].

Elevated D-dimer levels in plasma are not diagnostic for thromboembolism, and additional tests are needed to establish a diagnosis of VTE. The clinical value of D-dimer testing in conjunction with a low suspicion in a clinical decision rule is mostly confined to ruling out thromboembolism, when the test is below a certain threshold level; this is particularly evidence based for DVT of the lower extremity and for PE. In clinical practice, the value of a negative D-dimer test result for ruling out unusual forms of venous thrombosis, including UEDVT, cerebral vein thrombosis and splanchnic vein thrombosis, is less

\footnotetext{
* Corresponding author at: Venous Thromboembolism Unit, Internal Medicine Department, Hospital General Universitario Gregorio Marañón, Madrid, Spain.

E-mail address: pbdemelo@hotmail.com (P. Demelo-Rodríguez).
} 
established.

The use of D-dimer assays in the diagnostic workup of UEDVT has not been tested in formal trials and the available evidence comes from case series or cohort studies. Many UEDVT occur in hospitalized patients, often in association with malignant disease and central venous catheters, both situations that may increase the risk of falsely positive D-dimer results.

CVT accounts for $0.5 \%-1 \%$ of all strokes [8], with many patients being younger than 50 years [9]. When CVT presentation is acute ( $<7$ days), the risk of neurological sequelae is higher, making early diagnosis crucial in this entity [10]. This justifies the need for tools that can facilitate early diagnosis, such as D-dimer testing. This issue has been addressed by some authors, with contradictory results [11], and no clinical probability score has been validated so far.

SVT includes thrombosis in the superior mesenteric vein, splenic vein, portal vein and/or intrahepatic portal vein branches. Portal vein thrombosis (PVT) is a complication of liver cirrhosis and a cause of portal hypertension [12]. It deteriorates the liver function, increases the risk of bleeding and worsens the prognosis of patients with cirrhosis [13]. The role of D-dimer in the diagnosis of PVT in liver cirrhosis remains unclear.

Whether D-dimer can be useful in patients with suspected TUS remains controversial. In order to determine the value of D-dimer testing in the diagnosis TUS, we undertook a systematic review of the literature.

\section{Methods}

This systematic review followed the guidelines of the Preferred Reporting Items for Systematic Reviews and Meta-Analysis (PRISMA) statement.

Initially, the following TUS were included in the search: upper extremity deep vein thrombosis, cerebral vein thrombosis, retinal vein thrombosis, renal vein thrombosis, splanchnic vein thrombosis and ovarian vein thrombosis. However, due to the lack of results on retinal vein thrombosis, renal vein thrombosis and ovarian vein thrombosis, these types of TUS were finally excluded.

The search was conducted in MEDLINE and Cochrane Library for papers published in English and Spanish in the last 10 years (from January 1, 2008, to December 31, 2018), in adult humans, using the following terms: ("thrombosis in unusual sites" OR "upper extremity vein thrombosis" OR "cerebral vein thrombosis OR brain thrombosis OR brain thrombus OR cerebral thrombus OR intracranial thrombosis OR intracranial thrombus" OR "splanchnic thrombosis OR portal vein thrombosis OR splenic thrombosis OR mesenteric venous thrombosis OR Budd-Chiari syndrome OR Chiari's syndrome OR hepatic vein thrombosis OR hepatic venous outflow obstruction") AND (D-dimer OR D dimer OR fibrin fibrinogen degradation products).

We screened the reference lists of articles identified by the search strategy and included those judged relevant by title, abstract and full text. Articles were included if they were related to one of the predetermined types of TUS and provided information on D-dimer testing procedures. Case reports, articles not concerning humans or adult populations, and duplicates were excluded. Metaanalysis comprising articles already reviewed in this paper were also discarded.

Two authors (LOO and BK) screened the abstracts and full texts. In case of incertitude, the manuscript was revised concomitantly, and in case of disagreement, with the rest of the authors. Three authors (LOO, $\mathrm{BK}, \mathrm{ATCH})$ were involved in the quality assessment of the included papers.

The Newcastle-Ottawa quality assessment scale [14] was used to evaluate the value of each paper included in the manuscript, according to its study type. In this scale, papers are assigned stars according to their achievement in each category. This translates into a scale of good, fair or poor quality, according to the AHRQ standards. These evaluations are represented in Tables $1 \mathrm{a}$ and $1 \mathrm{~b}$.

\section{Results}

In the initial search, 220 articles were obtained. We discarded duplicates $(n=3)$, those search results not deemed relevant (not in adults $(n=2)$, not in humans $(n=11)$ and case reports $(n=35))$. Those abstracts not related to TUS (113) or with no mention of D-dimer (4) and manuscripts with other issues (13) were rejected. A total of 39 results were retained after the initial selection, based on title and abstract. Subsequently, a second selection based on full text was then performed, after which 23 articles remained (Fig. 1), comprising 3378 patients.

Details of the included manuscripts are described in Tables 1a and $1 b$.

\subsection{Upper extremity deep vein thrombosis}

Only two studies were identified in this category. They were both prospective and included 645 patients overall, with a cut-off level for Ddimer testing of $500 \mathrm{ng} / \mathrm{mL}$. A brief description is included in Table 2 .

Sartori et al. [15], in their study including 242 patients, determined that D-dimer testing had a high negative predictive value $(98 \%)$ in the diagnosis of UEDVT or upper extremity superficial vein thrombosis (UESVT). Of all patients enrolled, 22 had UEDVT and 35 had UESVT. They calculated a sensitivity of $92 \%$, in line with previous studies on Ddimer testing in populations with DVT or PE, with an estimated specificity of $60 \%$. They found that D-dimer testing is less reliable in patients with suspected UESVT than in those with UEDVT. The main flaw of this study, as stated by the authors, is that the diagnosis of upper extremity thrombosis was performed by ultrasonography, which may underestimate the diagnosis.

Van Es et al. [16] developed a predictive score (the Constans score) combining clinical features, laboratory results (including D-dimer at a cut-off of $500 \mathrm{ng} / \mathrm{mL}$ ) and ultrasonography. The area under the curve for the component of D-dimer testing observed was 0.72. However, their proposed algorithm presented a low efficiency in some subgroups with higher basal D-dimer levels, such as cancer patients. Besides, Ddimer testing evaluation was not the main objective of the authors, and it is only reviewed as part of the algorithm.

In summary, D-dimer testing might be recommended for the diagnosis of UEDVT, although it seems less useful in patients with UESVT and cancer. Nevertheless, the available evidence is very limited in this field, including only 645 patients in the last 10 years.

\subsection{Cerebral vein thrombosis}

Twelve articles related to cerebral vein thrombosis were identified.

Pfefferkorn et al. [17] observed that in a series of 32 patients with CVT, of whom 23 had D-dimer measurements, 13\% had a false negative result. This result concurs with Tanislav et al. [18], who also expressed concerns about false negative results. Nevertheless, they presented an area under the curve (ROC analysis) of 0.92 in a cohort of 239 patients, with a sensitivity and specificity of $90 \%$ when a cut-off level of $0.16 \mu \mathrm{g} /$ $\mathrm{mL}(160 \mathrm{ng} / \mathrm{mL})$ was used. They suggested that different cut-off levels for D-dimer testing in CVT should be perhaps considered.

Meng et al. [19], in a sample of 68 patients, documented a significant difference in D-dimer levels between patients with CVT and patients with non-thrombotic cerebral venous sinus stenosis, with a cutoff level of $500 \mu \mathrm{g} / \mathrm{L}$ ( $500 \mathrm{ng} / \mathrm{mL}$ ), suggesting that D-dimer might be a useful marker in the diagnosis of CVT. These studies illustrate uncertainty with regard to a cut off level for D-dimer testing in CVT.

Another issue to consider when using D-dimer in CVT is the timing of measurement. Two conditions are more likely to produce false-negative D-Dimer results: presentation as isolated headache and a longer interval between the onset of symptoms and the evaluation of the patient, since D-dimer values normalize over 1-3 weeks [9]. A subacute or chronic onset of symptoms occurs in over $50 \%$ of CVT patients. Alons 
Table 1a

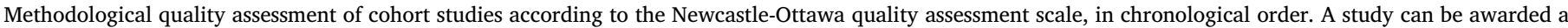

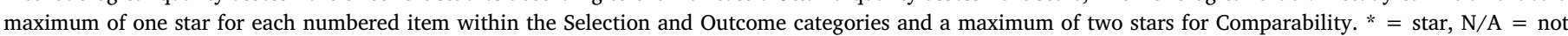
available, $\mathrm{P}=$ partially. UEDVT $=$ upper extremity deep vein thrombosis, CVT = cerebral vein thrombosis.

\begin{tabular}{|c|c|c|c|c|c|c|c|c|c|}
\hline & \multicolumn{4}{|l|}{ Selection } & \multirow{2}{*}{$\begin{array}{l}\text { Comparability } \\
\text { Comparability of } \\
\text { cohorts on the basis } \\
\text { of the design or } \\
\text { analysis controlled } \\
\text { for confounders }\end{array}$} & \multicolumn{3}{|l|}{ Outcome } & \multirow[t]{2}{*}{ Quality } \\
\hline & $\begin{array}{l}\text { Representativeness of } \\
\text { the exposed cohort }\end{array}$ & $\begin{array}{l}\text { Selection of } \\
\text { the non- } \\
\text { exposed } \\
\text { cohort }\end{array}$ & $\begin{array}{l}\text { Ascertainment of } \\
\text { exposure }\end{array}$ & $\begin{array}{l}\text { Demonstration that } \\
\text { outcome of interest } \\
\text { was not present at } \\
\text { start of study }\end{array}$ & & $\begin{array}{l}\text { Assessment } \\
\text { of outcome }\end{array}$ & $\begin{array}{l}\text { Was follow- } \\
\text { up long } \\
\text { enough for } \\
\text { outcomes to } \\
\text { occur }\end{array}$ & $\begin{array}{l}\text { Adequacy of } \\
\text { follow-up of } \\
\text { cohorts }\end{array}$ & \\
\hline \multicolumn{10}{|l|}{ UEDVT } \\
\hline Sartori 2015 & * & * & $*$ & * & $* *$ & * & $*$ & * & Good \\
\hline Van Es 2016 & * & * & $*$ & $*$ & $* *$ & $*$ & $*$ & * & Good \\
\hline \multicolumn{10}{|l|}{ CVT } \\
\hline $\begin{array}{l}\text { Pfefferkorn } \\
2009\end{array}$ & $*$ & $*$ & $*$ & $*$ & $*$ & * & * & * & Good \\
\hline Misra 2009 & * & * & $*$ & $*$ & - & * & - & $*$ & Poor \\
\hline $\begin{array}{r}\text { Tanislav } \\
2011\end{array}$ & $*$ & * & * & * & $* *$ & * & $*$ & $*$ & Good \\
\hline Vembu 2011 & * & N/A & * & * & $*$ & * & * & $*$ & Good \\
\hline Meng 2012 & * & $*$ & * & * & $* *$ & * & * & * & Good \\
\hline Sidhom 2013 & $*$ & * & * & * & $*$ & * & $*$ & * & Good \\
\hline $\begin{array}{l}\text { Hiltunen } \\
2013\end{array}$ & $*$ & * & * & * & $* *$ & * & $*$ & * & Good \\
\hline Meng 2014 & $*$ & * & * & N/A & $* *$ & * & $\mathrm{N} / \mathrm{A}$ & * & Good \\
\hline Alons 2015 & $*$ & $*$ & $*$ & N/A & $* *$ & $*$ & - & * & Good \\
\hline Wang 2016 & $*$ & $*$ & $*$ & $*$ & $* *$ & * & $*$ & * & Good \\
\hline $\begin{array}{r}\text { Yadegari } \\
2016\end{array}$ & * & N/A & * & - & $* *$ & $*$ & * & * & Fair \\
\hline \multicolumn{10}{|c|}{ Splanchnic thrombosis } \\
\hline Acosta 2008 & $*$ & $*$ & $*$ & - & $* *$ & * & - & * & Good \\
\hline Wang 2010 & $*$ & * & $*$ & $*$ & $* *$ & $*$ & $*$ & * & Good \\
\hline Donglei 2010 & $*$ & * & $*$ & N/A & $* *$ & $*$ & - & * & Good \\
\hline Zhang 2013 & $*$ & * & $*$ & $*$ & $* *$ & * & $*$ & * & Good \\
\hline Dai 2015 & $*$ & * & $*$ & * & $*$ & * & - & * & Good \\
\hline Fei 2015 & $*$ & * & $*$ & $*$ & $* *$ & * & $\mathrm{P}$ & * & Good \\
\hline $\begin{array}{c}\text { Wosiewicz } \\
2016\end{array}$ & $*$ & $*$ & $*$ & N/A & $* *$ & * & - & $*$ & Good \\
\hline Wei 2018 & $*$ & $*$ & $*$ & - & $* *$ & $*$ & * & * & Good \\
\hline
\end{tabular}

et al. [9] suggested that D-dimer testing shows a high negative predictive value in low risk patients, but recommended follow-up neuroimaging in high risk patients irrespective of the D-dimer value.

According to Meng et al. [20], D-dimer in CVT might be a reliable diagnostic tool in patients with an acute onset of symptoms. They presented a case-control study with 233 patients, in which $94.1 \%$ of the cases had an elevated D-dimer, with high sensitivity, specificity, positive predictive value and negative predictive value in the acute phase (within the first seven days).

In a retrospective study with 71 patients with CVT, Hiltunen et al. [21] concluded that D-dimer values can be used reliably to exclude acute intracranial thrombosis, but not in patients with subacute or chronic disease.

Wang et al. [22] also noted that D-dimer levels tend to be elevated in patients with acute/subacute CVT. They presented a prospective cohort study including 139 patients with CVT, describing an association between CVT with elevated D-dimer and underlying causes, such as prothrombotic conditions, pregnancy, puerperium, infection, systemic diseases and hematologic disorders. Patients with a shorter duration of symptoms, involvement of more venous sinuses and higher fibrinogen and blood glucose levels had higher plasma D-dimer levels. Apparently, the combination of subacute/chronic disease with additional procoagulant factors like diabetes, diminished the accuracy of the D-dimer test for ruling out CVT. Vembu et al. [23] reported a high prevalence of

\section{Table 1b}

Methodological quality assessment of the included studies for case-control studies according to the Newcastle-Ottawa quality assessment scale, in chronological order. A study can be awarded a maximum of one star for each numbered item within the Selection and Outcome categories and a maximum of two stars for Comparability. * = star, $\mathrm{N} / \mathrm{A}=$ not available. $\mathrm{CVT}=$ cerebral vein thrombosis.

\begin{tabular}{|c|c|c|c|c|c|c|c|c|}
\hline \multicolumn{4}{|l|}{ Selection } & \multirow{2}{*}{$\begin{array}{l}\text { Comparability } \\
\text { Comparability of cases } \\
\text { and controls on the } \\
\text { basis of the design or } \\
\text { analysis }\end{array}$} & \multicolumn{3}{|l|}{ Exposure } & \multirow[t]{2}{*}{ Quality } \\
\hline $\begin{array}{l}\text { Is the case } \\
\text { definition } \\
\text { adequate? }\end{array}$ & $\begin{array}{l}\text { Representativeness of } \\
\text { the cases }\end{array}$ & $\begin{array}{l}\text { Selection of } \\
\text { controls }\end{array}$ & $\begin{array}{l}\text { Definition of } \\
\text { controls }\end{array}$ & & $\begin{array}{l}\text { Ascertainment of } \\
\text { exposure }\end{array}$ & $\begin{array}{l}\text { Same method of } \\
\text { ascertainment for } \\
\text { cases and controls }\end{array}$ & $\begin{array}{l}\text { Non- } \\
\text { response } \\
\text { rate }\end{array}$ & \\
\hline$*$ & * & * & * & $* *$ & $*$ & * & N/A & Good \\
\hline \multicolumn{9}{|l|}{ hrombosis } \\
\hline$*$ & * & * & * & * & $*$ & N/A & N/A & Fair \\
\hline
\end{tabular}



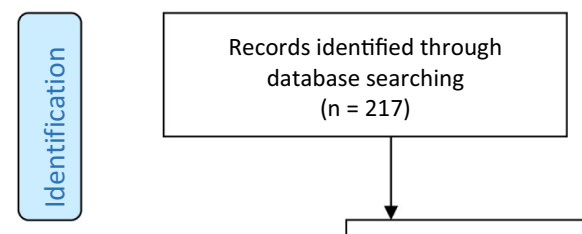$$
(n=217)
$$
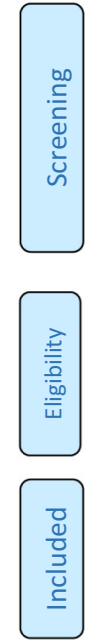

Additional records identified through other sources $(n=3)$

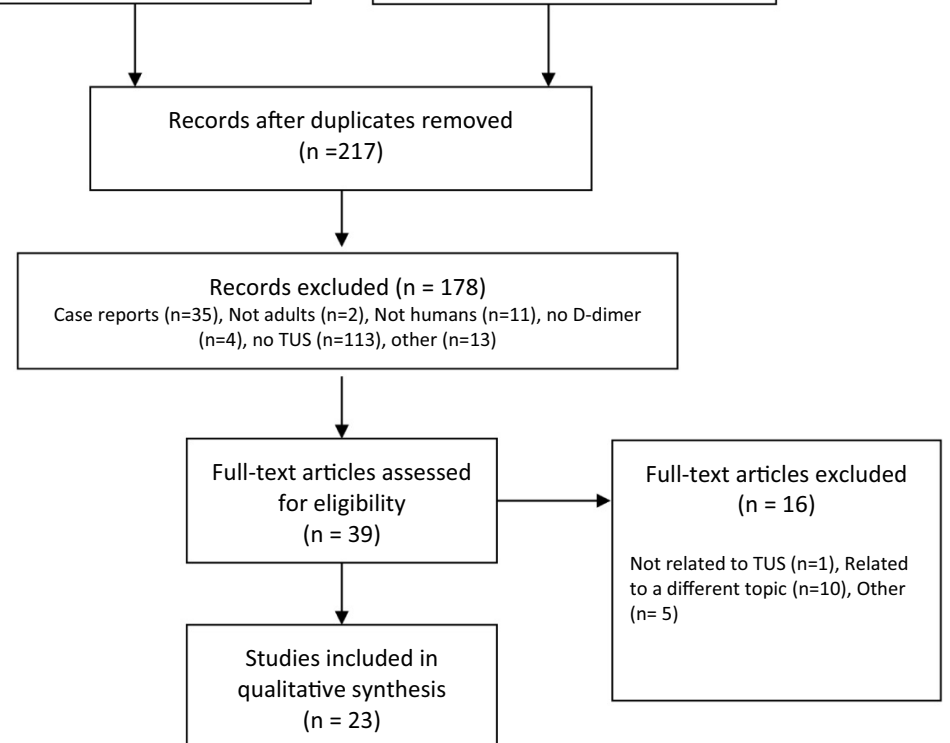

Fig. 1. Study selection. TUS $=$ thrombosis in unusual sites.

women with oral contraception and a sensitivity of $58 \%$ for D-dimer testing in their population. However, they also state that D-dimer testing was performed in only 36 out of 71 patients. On the other hand, Yadegari et al. [24] stated that in their population the most frequent risk factor for CVT was an underlying disease, with less than half women under oral contraception. D-dimer testing was performed in only 14 out 53 patients, and was elevated in 10 of them, disclosing a sensitivity of $71.4 \%$.

A study by Misra et al. [25] found that a D-dimer level above $500 \mu \mathrm{g} / \mathrm{L}(500 \mathrm{ng} / \mathrm{mL})$ does not correlate with the extent of the thrombosis, but it does with the duration of symptoms. Again, they agreed that D-dimer testing may be useful in acute CVT.

Concerning the clinical presentation, Hashami et al. [26] presented a case-control study proposing a cut-off value for D-dimer testing of $350 \mathrm{ng} / \mathrm{mL}$, suggesting that the severity of symptoms is associated with a higher D-dimer level.

In conclusion, D-dimer appears to be useful in the diagnosis of CVT, especially when presenting with acute-subacute symptoms. However, D-dimer was not performed in all patients in the studies reported, which might result in an incorrect estimation of the sensitivity and specificity. Besides, the D-dimer cut-off levels were also different in these articles. The role of D-dimer in patients with chronic CVT should be elucidated.

\subsection{Splanchnic vein thrombosis}

We identified nine articles on this topic, related to different populations: one of them concerning mesenteric venous thrombosis (MVT) and the remainder on portal vein thrombosis (PVT).

Acosta et al. [27] described a population of 51 patients with mesenteric venous thrombosis, in which 5 had D-dimer testing, of whom the mean D-dimer level was $1.0 \mathrm{mg} / \mathrm{L}(1.000 \mathrm{ng} / \mathrm{mL})$, five times the reference level. Although the number of patients with D-dimer levels in their population was very low, the authors suggest that D-dimer testing could be considered as a diagnostic marker in future prospective protocols.

A case-control study by Raffa et al. [12] determined that, in 50 patients with non-cirrhotic portal vein thrombosis, D-dimer levels were higher than in healthy controls, irrespective of the aetiology of PVT.
In a study by Fei et al. [28], 137 patients with hepatitis virus-related cirrhotic portal hypertension who underwent devascularisation were screened for D-dimer levels, comparing patients with versus those without PVT. For a cut-off value of $500 \mathrm{ng} / \mathrm{mL}$, the level of D-dimer in the PVT group was clearly higher after devascularisation, with a sensitivity of $83.8 \%$, a negative predictive value of $80.7 \%$ and an area under the curve of 0.83 , indicating that D-dimer could be a diagnostic marker for PVT in patients with hepatitis virus-related cirrhotic portal hypertension undergoing devascularisation.

Zhang et al. [13] described a population of 152 cirrhotic patients with and without PVT, in which D-dimer was significantly higher in the PVT group through all three Child-Pugh classes, being a risk factor for PVT formation with an odds ratio of 15.6. They also calculated new cutoff values for D-dimer testing for each Child-Pugh class. As the liver function deteriorates, the area under the curve diminished, although the negative predictive value remained over $80 \%$ in all three classes.

In a second study from this group [29], patients with liver cirrhosis caused by hepatitis B or C or alcohol, were additionally divided in patients with or without PVT. Results were concordant with the previous study, where the lowest cut-off value could be seen in the ChildPugh class A and the area under the curve decreased as the Child-Pugh class increased, with a modest 0.69 in the Child-Pugh class C.

Wosiewicz et al. [30] selected a population of 49 hospitalized patients with cirrhosis. Their results were discordant with those of Zhang et al., the cut-off value increased with the Child-Pugh class, as did the area under the curve, the sensitivity and the PPV. It must be noticed that the Child-Pugh class $C$ was not included in the calculations due to the low number of patients in this class, and all causes of cirrhosis were included in this study.

Wang et al. [31] recruited 82 patients with cirrhosis related portal hypertension undergoing splenectomy, of whom $30 \%$ developed PVT after the surgery. In this study, for a cut-off value of $500 \mu \mathrm{g} / \mathrm{mL}$ $(500 \mathrm{ng} / \mathrm{mL})$, the area under the curve was 0.88 , with a sensitivity of $88.9 \%$ and a specificity of $78.2 \%$. Another study by Wei et al. [32] on 144 patients described a sensitivity of $83.5 \%$ on the first day after surgery. However, they propose other biomarkers that could be more valuable in the early prediction of PVT in this subgroup of patients.

In a retrospective study by Dai et al. [33], including 66 cirrhotic 


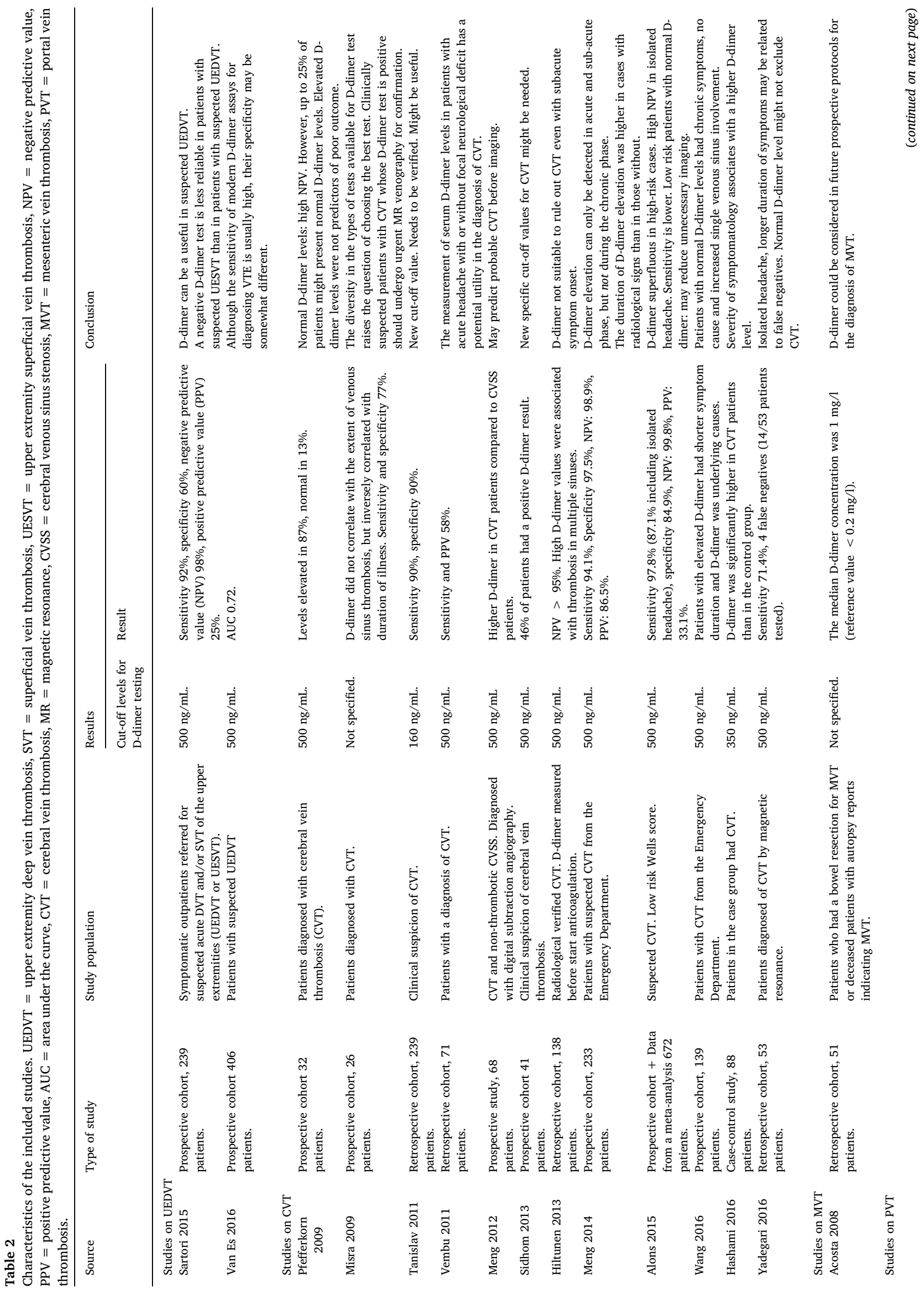


patients with an imaging test and a D-dimer test, the mean D-dimer level was not different between patients with or without PVT, in contrast to the results by Zhang et al. [29]. The area under the curve for PVT prediction was 0.61 . The subgroup analysis showed low AUC values for patients without splenectomy and Child-Pugh classes A and B. However, the AUC for Child-Pugh class C patients was 0.75, with a sensitivity of $100 \%$ for a cut-off value of $900 \mathrm{ng} / \mathrm{mL}$.

In brief, although the number of patients included in this category ( $n=933$ ) is substantial, there is a heterogeneity in the populations included, the D-dimer cut-off levels used and the methods in each manuscript. This implies that the results might not be completely valid for the general population. The low number of patients in Child-Pugh class $\mathrm{C}$, in some cases, has entailed the exclusion of these patients from some manuscripts, thus diminishing the level of evidence available for these patients.

\section{Discussion}

Clinically, D-dimer testing is mostly confined to ruling out VTE in conjunction with a low suspicion assessed with a clinical decision rule. Its diagnostic value has been well established in PE and lower extremity DVT, and it is widely used in daily clinical practice for those indications.

However, the usefulness of a negative D-dimer for ruling out venous TUS is less well established. TUS, such as cerebral vein thrombosis or splanchnic vein thrombosis, is much less frequent than DVT or PE, and data about its pathogenesis and diagnosis are scarce. Evidence is derived mostly from case series and small cohort or case-control studies, and is therefore less robust. Although D-dimer might be useful in the diagnosis of patients with TUS, there are differences depending on onset and duration of the symptoms, the testing method employed or other influencing factors that may impact the result of the test. D-dimer cutoff levels may also differ from one type of TUS to another. For example, in patients with liver cirrhosis, the degree of liver dysfunction appears to be directly related to the D-dimer level.

All included papers concur that there is a significant lack of evidence on the usefulness of D-dimer testing in TUS. However, and although the most important types are those included in this review (UESVT, UEDVT, CVT and splanchnic vein thrombosis), TUS include many other variants, such as retinal or renal vein thrombosis (not hereby discussed due to the lack of related evidence). Given the rather rare presentation of TUS, reliable evidence could only come from large case series from dedicated centres or multicentre studies, preferably on one particular manifestation of TUS.

According to the reviewed manuscripts, D-dimer testing could be useful test in the diagnosis of UEDVT, especially when combined with clinical parameters. One manuscript [16] even proposes a clinical decision rule combining D-dimer testing and clinical parameters. If validated, this tool might improve the diagnosis of UEDVT.

In patients with acute CVT, presenting with symptoms lasting $<7$ days, D-dimer testing could also be useful. However, according to the presented results, this value should be combined with a clinical tool in subacute and chronic CVT, where a false negative result is more probable.

D-dimer testing may also be useful in certain patient subpopulations with a clinical suspicion of mesenteric vein thrombosis or PVT, but current evidence is still insufficient to routinely include D-dimer testing in the diagnostic workup of such patients. The results from the different studies are quite heterogeneous, as are the included patient groups. Ddimer testing might be useful in the diagnosis of venous mesenteric thrombosis alone (without portal vein involvement), but this evidence comes from one single study. Concerning PVT, the level of evidence is lower in Child-Pugh class $\mathrm{C}$ patients due to the inferior number of patients included in these studies. In patients with hepatic cirrhosis related portal hypertension undergoing splenectomy, D-dimer may also be useful in the diagnosis of PVT. However, in cirrhotic patients of all 
Table 3

D-Dimer test used in each study.

\begin{tabular}{llll}
\hline Study & Quantitative assays & Qualitative assays & Not specified \\
\hline Pfefferkorn 2009 & & X & \\
Misra 2009 & & & \\
Tanislav 2011 & X & & \\
Vembu 2011 & X & & \\
Sidhom 2013 & X & X \\
Hiltunen 2013 & X & X \\
Meng 2014 & X & \\
Alons 2015 & X & \\
Wang 2016 & & & \\
Hashami 2016 & X & \\
Yadegari 2016 & X & \\
Sartori 2015 & X & \\
Van Es 2016 & X & \\
Acosta 2008 & X & \\
Wang 2010 & X & \\
Donglei 2010 & X & \\
Raffa 2012 & X & \\
Zhang 2013 & X & \\
Dai 2015 & X & \\
Fei 2015 & & & \\
Wosiewicz 2016 & X & & \\
Wei 2018 & X & \\
\hline
\end{tabular}

aetiologies [33], the D-dimer testing showed only modest AUC values. Further research should help determine whether this test is applicable to the general cirrhotic population.

Given the high variability of D-dimer tests worldwide, using different measurement units, there is a need for standardization, not only for research purposes, but also for clinical use. This could lead to the hypothesis that the extensive lack of consistency throughout different manuscripts could be attributed to the fact that many different tests have been employed. On the other side, there is also a vast heterogeneity of the patients included. However, there is not enough evidence to demonstrate whether one factor (population) or the other (tests) have a larger impact on these results. Presumably, both of them have an impact, and measures should be taken to improve the existing evidence on this topic.

Notwithstanding, the cut-off levels for D-dimer testing provided in some of the included manuscripts seemed to be rather higher than those accepted for DVT and PE. Some authors expose that this could be secondary to the more frequent presence of risk factors in patients with TUS, which could imply a different baseline D-dimer level [27]. On the other hand, some others believe that D-dimer usual cut-off levels are not acceptable for TUS since the thrombus might be more compact [21]. There is thus a lack of standardized cut-off levels for D-dimer testing in TUS that should be addressed.

All this could also explain, at least partially, the variation in sensitivity and specificity percentages for D-dimer testing seen on these manuscripts, as stated in Table 2 .

Clinically, the main objective of a D-dimer test is to use it to support the exclusion of a thrombotic event in a safe manner. Given the moderate to high sensitivity, but persistently poor specificity of D-dimer testing, this goal can be accomplished if combined with a clinical decision rule, which is also not sensitive enough by itself. However, in some cases it has been stated that D-dimer testing might prove useful in the diagnosis of TUS, as previously described. This is especially useful considering that clinical decision rules are notoriously absent in TUS, compared to PE or DVT, and need to be developed.

Since D-dimer testing shows rather heterogeneous values according to the patient's characteristics and testing method employed, future research should aim at ameliorating the combination of D-dimer and probably other biomarkers [32,33], along with clinical decision tools, to develop diagnostic algorithms for all relevant patient populations and specific types of thrombosis [17]. These combinations will enhance the sensitivity in the diagnosis of TUS and thus ensure patient's safety.
This review shows that TUS, although part of the venous thromboembolism sphere, should be regarded as a different entity than PE or DVT. Specifically, the diagnostic procedures should be individualized for TUS and, more precisely, for each type of TUS.

\subsection{Limitations}

Our review presents certain limitations. First, although we looked over a 10-year period, there were few papers concerning the issue of Ddimer testing in TUS. Some articles might have been missed due to the research terms. Also, since the search was limited to studies published in English or Spanish languages, literature in other languages was not included.

The included studies include very different populations. Although all patients suffer from TUS, there are many different types. Also, they measure D-dimer levels using different testing methods, sometimes not clearly stated in the text (Table 3). Every author proposes a new cut-off D-dimer value for their own population. The heterogeneity of these procedures challenges the generalization of their results to the general population.

\section{Conclusion}

The usefulness of D-dimer testing in the diagnostic workup of patients with suspected thrombosis in unusual sites is poorly documented. D-dimer testing alone cannot be currently recommended for the diagnosis of TUS as a first line diagnostic tool. D-dimer testing combined with a clinical decision rule may be useful for the diagnosis of UEDVT. However, the usefulness of D-dimer testing in the absence of clinical decision rule is still debatable in CVT and SVT. Furthermore, no conclusions can be drawn on the other forms of thrombosis of unusual sites. Further research is needed to broaden the evidence.

\section{References}

[1] M. Di Nisio, N. van Es, H.R. Büller, Deep vein thrombosis and pulmonary embolism, Lancet 388 (2016).

[2] J.J. Shatzel, M. O'Donnell, S.R. Olson, et al., Venous thrombosis in unusual sites: A practical review for the hematologist, Eur J Haematol. 102 (1) (2019) 53-62.

[3] P.S. Wells, D.R. Anderson, J. Bormanis, et al., Value of assessment of pretest. probability of deep-vein thrombosis in clinical management, Lancet. 350 (9094) (1997).

[4] P.S. Wells, J.S. Ginsberg, D.R. Anderson, et al., Use of a clinical model for safe management of patients with suspected pulmonary embolism, Ann Intern Med. 129 (12) (1998).

[5] T. van der Hulle, W. Cheung, S. Kooij, et al., Simplified diagnostic management of suspected pulmonary embolism (the YEARS study): a prospective, multicentre, cohort study, The Lancet. 390 (10091) (2017) 289-297.

[6] J. Wicki, T.V. Perneger, A.F. Junod, et al., Assessing clinical probability of pulmonary embolism in the emergency ward: a simple score, Arch Intern Med. 161 (1) (2001).

[7] J.I. Weitz, J.C. Fredenburgh, J.W. Eikelboom, A test in context: D-dimer, J Am Coll Cardiol. 70 (19) (2017).

[8] F. Dentali, A. Squizzato, C. Marchesi, et al., D-dimer testing in the diagnosis of cerebral vein thrombosis: a systematic review and a meta-analysis of the literature, J Thromb Haemost. 10 (4) (2012).

[9] I.M. Alons, K. Jellema, M. Wermer, A. Algra, D-dimer for the exclusion of cerebral venous thrombosis: a meta-analysis of low risk patients with isolated headache, BMC Neurol. 15 (2015).

[10] Y. Sidhom, M. Mansour, M. Messelmani, et al., Cerebral venous thrombosis: clinical features, risk factors, and long-term outcome in a Tunisian cohort, J Stroke Cerebrovasc Dis. 23 (6) (2014) 1291-1295.

[11] C. Kosinski, M. Mull, M. Schwarz, et al., Do Normal D-dimer Levels Reliably Exclude Cerebral Sinus Thrombosis? Stroke. 35 (12) (2004) 2820-2825.

[12] S. Raffa, J.C. Reverter, S. Seijo, et al., Hypercoagulability in patients with chronic noncirrhotic portal vein thrombosis, Clin Gastroenterol Hepatol. 10 (1) (2012).

[13] D. Zhang, J. Hao, N. Yang, Protein C and D-dimer are related to portal vein thrombosis in patients with liver cirrhosis, J Gastroenterol Hepatol. 25 (1) (2010).

[14] G. Wells, B. Shea, D. O'Connell, J. Peterson, V. Welch, M. Losos, et al., Ottawa Hospital Research Institute [Internet], [cited 21 December 2019]. Available from Ohri.ca, http://www.ohri.ca/programs/clinical_epidemiology/oxford.asp, (2019).

[15] M. Sartori, L. Migliaccio, E. Favaretto, et al., D-dimer for the diagnosis of upper extremity deep and superficial venous thrombosis, Thromb Res. 135 (4) (2015).

[16] N. Van Es, S.M. Bleker, M. Di Nisio, et al., A clinical decision rule and D-dimer testing to rule out upper extremity deep vein thrombosis in high-risk patients, 
Thromb Res. 148 (2016).

[17] T. Pfefferkorn, I. Crassard, J. Linn, et al, Clinical features, course and outcome in deep cerebral venous system thrombosis: an analysis of 32 cases, J Neurol. 256 (11) (2009)

[18] C. Tanislav, R. Siekmann, N. Sieweke, et al., Cerebral vein thrombosis: clinical manifestation and diagnosis, BMC Neurol. 10 (2011).

[19] R. Meng, D. Dornbos 3rd, L. Meng, et al., Clinical differences between acute CVST and non-thrombotic CVSS, Clin Neurol Neurosurg. 114 (9) (2012).

[20] R. Meng, X. Wang, M.W. Hussain, et al., Evaluation of plasma D-dimer plus fibrinogen in predicting acute CVST, Int J Stroke. 9 (2) (2014).

[21] S. Hiltunen, J. Putaala, E. Haapaniemi, et al., D-dimer and clinicoradiologic features in cerebral venous thrombosis, J Neurol Sci. 327 (1-2) (2013).

[22] H.F. Wang, C.Q. Pu, X. Yin, et al., D-dimers (DD) in CVST, Int J Neurosci. 127 (6) (2017).

[23] P. Vembu, J.K. John, M.I. Mohammed, A.F. Al-Shubaili, Cerebral venous thrombosis in Kuwait. Clinical presentation, risk factors, and management, Neurosciences (Riyadh). 16 (2) (2011).

[24] S. Yadegari, A. Ghorbani, S. Miri, et al., Clinical features, risk factors, and outcome of cerebral venous thrombosis in Tehran, Iran, Journal of Neurosciences in Rural Practice. 7 (4) (2016) 554-558.

[25] U.K. Misra, J. Kalita, V. Bansal, D-dimer is useful in the diagnosis of cortical venous sinus thrombosis, Neurol India 57 (1) (2009).

[26] L. Hashami, V. Rakhshan, H. Karimian, M. Moghaddasi, Diagnostic value of D-
Dimer's serum level in Iranian patients with cerebral venous thrombosis, Neurol Int. 8 (2) (2016 Jun 15).

[27] S. Acosta, A. Alhadad, P. Svensson, O. Ekberg, Epidemiology, risk and prognostic factors in mesenteric venous thrombosis, Br J Surg. 95 (10) (2008).

[28] Y. Fei, G.Q. Zong, J. Chen, R.M. Liu, Evaluation of the value of d-dimer, P-selectin, and platelet count for prediction of portal vein thrombosis after devascularization, Clin Appl Thromb Hemost. 22 (5) (2016).

[29] D.L. Zhang, J.Y. Hao, N. Yang, Value of D-dimer and protein S for diagnosis of portal vein thrombosis in patients with liver cirrhosis, J Int Med Res. 41 (3) (2013).

[30] P. Wosiewicz, M. Żorniak, M. Hartleb, et al., Portal vein thrombosis in cirrhosis is not associated with intestinal barrier disruption or increased platelet aggregability, Clin Res Hepatol Gastroenterol. 40 (6) (2016).

[31] L. Wang, G.J. Liu, Y.X. Chen, et al., Combined use of D-dimer and P-selectin for the diagnosis of splenic or portal vein thrombosis following splenectomy, Thromb Res. 125 (5) (2010)

[32] Y. Wei, X. Chen, H. Shen, et al., P-selectin level at first and third day after portal hypertensive splenectomy for early prediction of portal vein thrombosis in patients with cirrhosis, Clinical and Applied Thrombosis/Hemostasis. 24 (9_suppl) (2018) 76S-83S.

[33] J. Dai, X. Qi, Y.Q. Peng, et al., Association between D-dimer level and portal venous system thrombosis in liver cirrhosis: a retrospective observational study, Int J Clin Exp Med. 8 (9) (2015). 